\title{
Bilateral oculomotor nerve palsies due to vascular conflict
}

\author{
Erasmo Barros da Silva Jr. ', Ricardo Ramina', Murilo Sousa de Meneses ${ }^{1}$, \\ Pedro André Kowacs², Erasmo Barros da Silva ${ }^{3}$
}

Oculomotor nerve palsy is frequently caused by an aneurismal compression and diabetes mellitus. Brainstem infarction, cavernous sinus tumors and other intracranial lesions are well known causes of oculomotor palsy also. However, neurovascular conflict causing oculomotor nerve disturbances are rare $^{1-4}$. After the advent of high quality MRI and neuroimaging improvements, the diagnosis of such atypical neurovascular conflicts in symptomatic patients became quite simple ${ }^{5,6}$. The case of a patient with bilateral oculomotor disorder with MRI imaging of the head showing a right oculomotor nerve compression by the right posterior cerebral artery and a left oculomotor nerve compression by the left superior cerebellar artery is reported and discussed.

\section{CASE}

This case report has been approved by the ethics committee of our institution and the patient consented with the publication. A 56 year old man with a chronic bilateral oculomotor nerve paresis was seen at our clinic. He has this non-progressive deficit for more than 15 years without any associated conditions and has been well-adapted to his condition. After an ophthalmologic evaluation, a neurological screening was suggested to exclude the possibility of intracranial mass or aneurysm. He had neither a metabolic disease nor a history of a familial neurological disorder. At physical examination, the patient showed a bilateral ophthalmoplegia, with extrinsic ocular movements depending on the activity of the IV and the VI cranial nerves and an associated partial bilateral ptosis (Fig
1). There were no pupillary abnormalities. All laboratorial results were within normal limits. An investigation to exclude myasthenia gravis was proceeded, with normal thoracic CT-scan and laboratorial tests. A therapeutic test with pyridostigmine failed to improve the III ${ }^{\text {rd }}$ nerves function. A T2-weighted MRI imaging of the head revealed bilateral oculomotor nerve compression due to vascular conflicts, the right conflict caused by the right posterior cerebral artery and the left caused by the left superior cerebellar artery (Fig 2). A CTangiography showed no aneurysm or relevant abnormalities. A two-step surgical approach was suggested to the patient who refused to be operated on because he is well-adapted to the ophtalmoplegia and stated that it does not interfere on his daily activities.

\section{DISCUSSION}

Vascular compression of a cranial nerve at the brainstem can cause several syndromes. Most of the neurovascular conflicts found in the literature are reported to occur within the cerebellopontine angle, with an arterial loop or a hindbrain vein compressing a cranial nerve, from the IV to the XII cranial nerves. Trigeminal neuralgia, hemifacial spasm, vertigo and glossopharyngeal neuralgia are well-known hyperactive dysfunctions secondary to a vascular compression of the V, VII, VIII and IX cranial nerves, respectively, mostly on the junction area between the central and the peripheral myelin. Surgical microvascular decompression is the approach of choice to treat many of the cases bearing these conditions ${ }^{7}$.

\footnotetext{
Correspondence
Erasmo Barros da Silva Jr.
Rua Jeremias Maciel Perretto 300
81210-310 Curitiba PR - Brasil
E-mail: teeth@uol.com.br

Correspondence
Erasmo Barros da Silva Jr.
Rua Jeremias Maciel Perretto 300
81210-310 Curitiba PR - Brasil
E-mail: teeth@uol.com.br

Correspondence
Erasmo Barros da Silva Jr.
Rua Jeremias Maciel Perretto 300
81210-310 Curitiba PR - Brasil
E-mail: teeth@uol.com.br

Correspondence
Erasmo Barros da Silva Jr.
Rua Jeremias Maciel Perretto 300
81210-310 Curitiba PR - Brasil
E-mail: teeth@uol.com.br

Received 15 May 2009

Accepted 29 September 2009
}

\section{PARALISIA BILATERAL DO NERVO OCULOMOTOR POR CONFLITO NEUROVASCULAR}

${ }^{1}$ Departament of Neurosurgery, Instituto de Neurologia de Curitiba, Curitiba PR, Brazil; ${ }^{2}$ Department of Neurology, Instituto de Neurologia de Curitiba, Curitiba PR, Brazil; ${ }^{3}$ Neurological Clinic of Paraíba, João Pessoa PB, Brazil. 

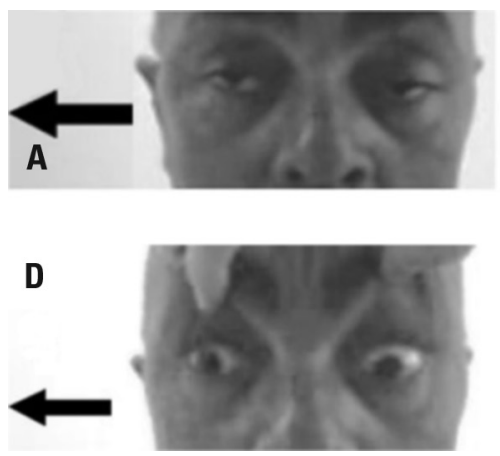

B

$\mathbf{E}$

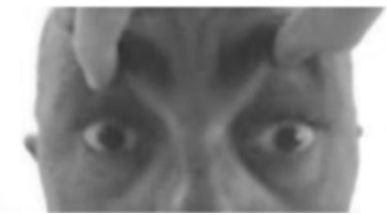

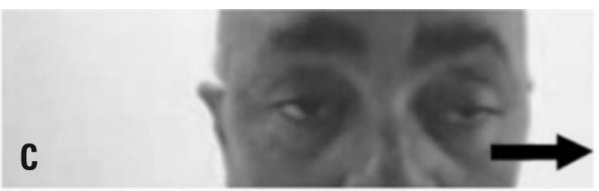

$\mathbf{F}$

Fig 1. [A] Bilateral ophthalmolplegia. [A and D] Left oculomotor plegia; [B and E] Partial bilateral ptosis; [C and F] Right oculomotor plegia.
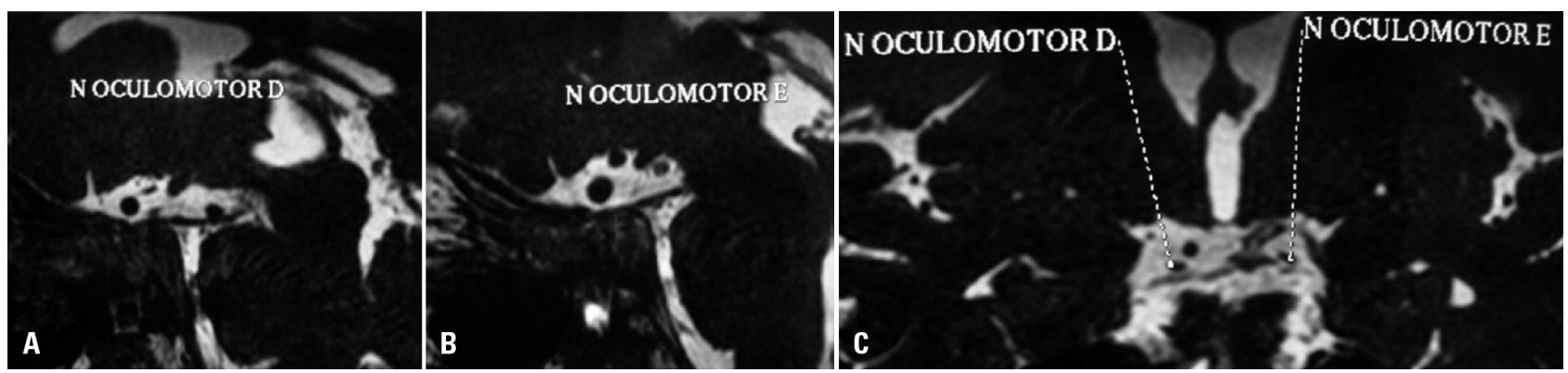

Fig 2. MRI showing the vascular conflict. [A] Sagital view, right oculomotor nerve and right PCA; [B] Sagital view, left oculomotor nerve and left SCA; [C] Coronal view showing both conflicts.

Intracranial aneurysm compression of the oculomotor nerve in the subarachnoid space is the commonest cause of III ${ }^{\text {rd }}$ nerve dysfunction. An oculomotor compression by atherosclerotic, abnormally positioned or abnormal vessels has also been reported ${ }^{1}$. Diabetes mellitus can also lead to an ischemic oculomotor nerve dysfunction usually sparing the pupil. Intracranial lesions, brainstem infarction, trauma and cavernous sinus tumors are known causes of oculomotor palsy without pupil sparing ${ }^{4}$.

Nonaneurysmal compression of the oculomotor nerve is a condition rarely reported in the literature. The case of a patient in whom a duplicated left superior cerebellar artery, a prominent posterior communicating artery and a posterior cerebral artery diagnosed by MRI leading to compression of the oculomotor nerve causing anisocoria was reported by Albayram et $\mathrm{al}^{1}$. Mulderink et al reported a case presenting with a III $^{\text {rd }}$ nerve palsy due to a direct vascular compression by a large dilatation of the left posterior communicating artery ${ }^{2}$. Nakagawa et al reported a case of bilateral oculomotor nerve paresis due to compression by arteriosclerotic left and right posterior cerebral arteries ${ }^{3}$. Suzuki et al described a case presenting with a left oculomotor palsy due to an oculomotor nerve pinch between the left posterior cerebral artery and the left superior cerebellar artery ${ }^{4}$. The diagnosis was made during the surgical clipping of an aneurysm at the junction of the left internal carotid and the posterior communicating arteries, found to be unrelated with the III ${ }^{\text {rd }}$ nerve dysfunction. The last two cases were successfully treated by microvascular decompression with palsy improvement.

In the case presented in this article, an idiopathic cause of a chronic bilateral oculomotor nerve paresis was discarded after a MRI imaging of the head, which revealed the bilateral neurovascular conflict. These findings could not be shown by angiography but were consistent enough to be regarded as the cause of the bilateral III ${ }^{\text {rd }}$ nerve palsy.

The progress in neuroimaging methods led to a better demonstration of the anatomical relationship between vessels and cranial nerves such as those demonstrated by high-quality MRI. The 3D Fourier constructive interference steady state sequences (3D-CISS) and 3D time-offlight sequences (3D-TOF) enable a detailed study of the anatomy and of the vascular relationship of the cisternal segment of the oculomotor nerves. In the investigation for oculomotor nerve dysfunction, abnormal compression related to vessels and lesions may be easily detected by these methods ${ }^{6}$. Once a vascular conflict is demonstrated, microvascular decompression may be an effective treatment option. Patients presenting with a III ${ }^{\text {rd }}$ nerve dysfunction previously diagnosed as bearing an id- 
iopathic cranial neuropathy may benefit from a detailed neuroimaging investigation.

Vascular compression of the oculomotor nerve causing ophthalmoplegia is a very rare condition. Posterior cerebral artery, superior cerebral artery and a PComA may be the arteries involved in the conflict, successfully showed with high-quality MRI investigation. Like other types of neurovascular conflicts, as trigeminal neuralgia and hemifacial spam, the microvascular decompression is a choice of treatment for nerve function improvement in these patients.

\section{REFERENCES}

1. Albayram S, Ozer H, Sarici A, Murphy K, Miller N. Unilateral mydriasis without ophthalmoplegia: a sign of neurovascular compression? Case report. Neurosurgery 2006;58:582-583.
2. Mulderink TA, Bendok BR, Yapor WY, Batjer HH. Third nerve paresis caused by vascular compression by the posterior communicating artery. J Stroke Cerebrovasc Dis 2001;10:139-141.

3. Nakagawa H, Nakajima S, Nakajima Y, Furuta Y, Nishi O, Nishi K. Bilateral oculomotor nerve palsies due to posterior cerebral arterial compression relieved by microvascular decompression: case report. Neurol Méd Chir (Tokyo) 1991;31:45-48

4. Suzuki K, Muroi A, Kujiraoka Y, Takano S, Matsumura A. Oculomotor palsy treated by microvascular decompression. Surg Neurol 2008;70:210-212.

5. Liang C, Du Y, Lin X, Wu L, Wu D, Wang X. Anatomical features of the cisternal segment of the oculomotor nerve: neurovascular relationships and abnormal compression on magnetic resonance imaging. J Neurosurg 2009; Doi: 10.3171/2009.1.JNS081185

6. Sun X, Liang C, Liu C, Liu S, Deng K, He J. Oculomotor paralysis: 3D-CISS MR imaging with MPR in the evaluation of neuralgic manifestation and the adjacent structures. Eur J Radiol 2008; Doi:10.1016/j.ejrad.2008.11.004.

7. McLaughlin MR, Jannetta PJ, Clyde BL, Subach BR, Comey CH, Resnick DK. Microvascular decompression of cranial nerves: lessons learned after 4400 operations. J Neurosurg 1999;90:1-8. 